Acta Botanica Mexicana dedica este número a la memoria de Miguel Ángel Martínez Alfaro, ameritado estudioso de la etnobotánica, miembro del Consejo Editorial de esta revista. 


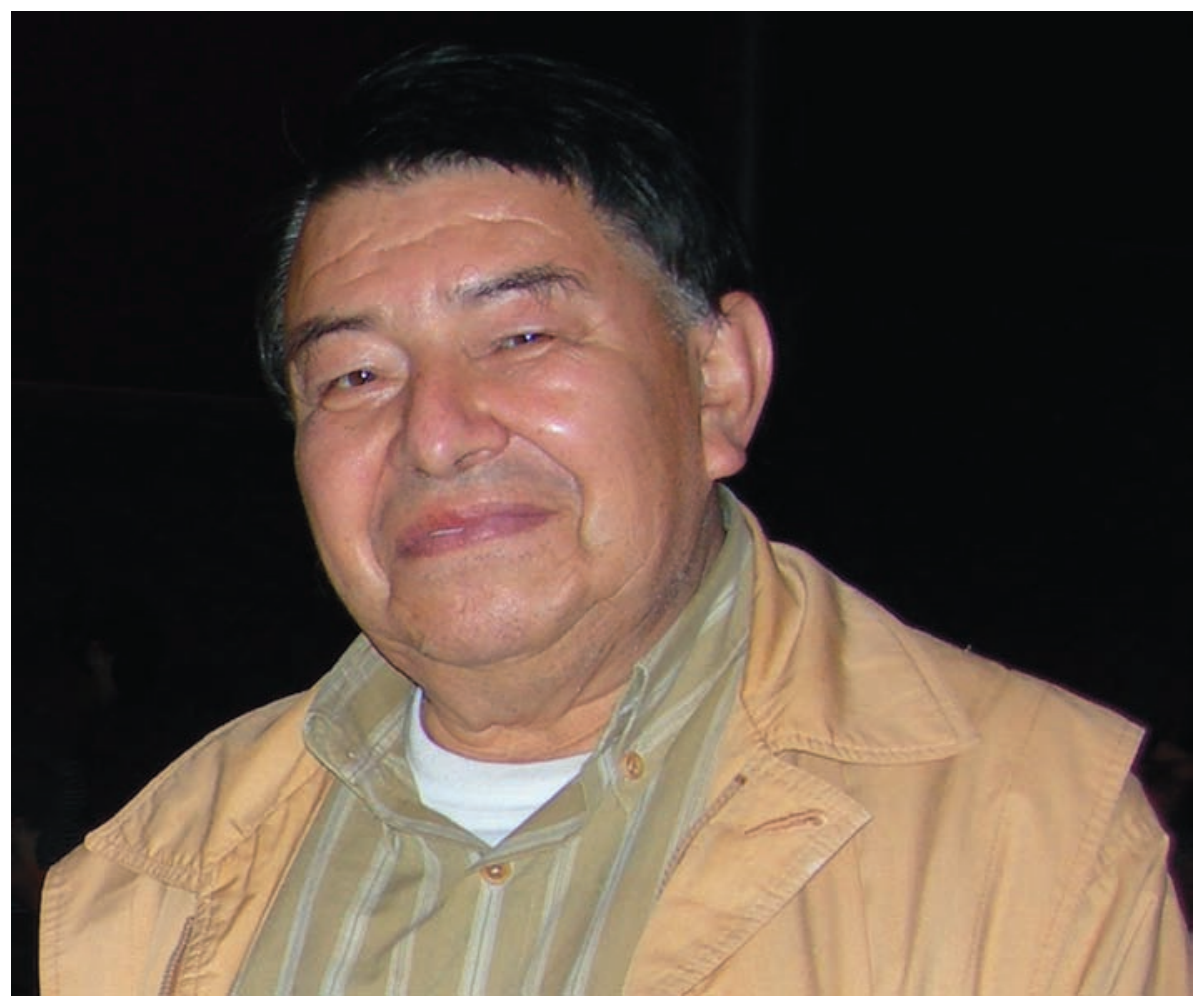

\section{MIGUEL ÁNGEL MARTÍNEZ ALFARO (1942-2007)}

Miguel Ángel Martínez Alfaro nació el 23 de octubre de 1942 en la ciudad de México, específicamente en Tlalpan, en el seno de una familia trabajadora, su padre era empleado de la Casa Bocker y su madre, para ayudar a la economía familiar, se dedicaba a la costura. Era la época de la segunda guerra mundial y se festejaba el 450 aniversario del descubrimiento de América, la música que se escuchaba era la de las grandes bandas y se bailaba el swing.

Desde niño le interesó la naturaleza, siempre con una mente inquieta y de investigación hacía disecciones a las lagartijas para saber cómo eran por dentro, admiraba los árboles y guardaba las hojas y flores en sus cuadernos. Estudió la primaria en el colegio José María Vilaseca Esparza, que todavía lo podemos ver sobre la calzada de Tlalpan, ahí le pusieron de apodo el "Niño Diez” debido a que siempre sacaba las mejores calificaciones y sobre todo le gustaba estudiar y leer, a tal grado, que les pidió a sus papás que lo suscribieran a las colecciones de cuentos de ciencia 
y ficción como como “Titanes Planetarios”, de religión "Vidas Ejemplares” y de historia novelada "Leyendas de América”, así como a las revistas de temas generales de la época; este afán de lectura le valió que fuera en su vida adulta, uno de esos seres enciclopedistas que al preguntarle por cualquier tema siempre tenía la respuesta correcta.

En la Escuela Secundaria Diurna Núm. 1, situada en las calles de Regina, comenzó a gustar de la música, inscribiéndose en el coro de dicha escuela. Los viajes de regreso a casa en tranvía eran de un gran gusto, se bajaba antes de llegar a la parada para observar las plantas que crecían entre las vías; también en estos años cincuenta, con el lanzamiento de los sputnik soviéticos, se inició en el estudio de la bóveda celeste identificando las constelaciones y demás astros, lo cual le sirvió en su vida profesional cuando siendo de noche, tenía que caminar por las montañas, para llegar a alguna comunidad de la Sierra Norte de Puebla y guiarse solamente por las estrellas, esta cualidad y conocimiento asombraba a cualquiera que andaba con él.

Al terminar sus estudios secundarios decidió entrar al seminario, creía tener vocación sacerdotal, lo cual fue bueno porque se dio cuenta de que su camino debía ser otro, sin embargo siguió interesado en la Teología y, en tiempos subsecuentes, dio clases de esta materia en el Centro Cultural Universitario.

En la Escuela Nacional Preparatoria Núm. 1, descubrió el conocimiento universal, la ciencia y el arte y logró una sólida cultura general, teniendo como maestros a Agustín Yánez en Literatura y Manuel Ruíz Oronoz en Biología, entre otros. Era la época final del rock and roll y comienzo del twist.

La elección de una profesión no fue difícil para Miguel Ángel, ya que su interés genuino por el estudio de la naturaleza era palpable, y es así que en los años sesenta ingresa a la Facultad de Ciencias de la Universidad Nacional Autónoma de México para estudiar Biología. En esta época de formación, la materia que le dejó una huella fue la de Botánica, que impartía su querida maestra María Agustina Batalla. Los tiempos eran cambiantes, se estaba conformando la filosofía hippie acompañada por la música de los Beatles.

Llegado el momento tuvo que tomar camino al plano profesional, primeramente buscando un trabajo y luego cumpliendo con el requisito de elaborar una tesis.

Él decía que tuvo suerte de encontrar un trabajo en la Comisión Nacional para el Estudio de las Dioscóreas, donde sus maestros eran el Dr. Efraím Hernández Xolocotzi, el Dr. Arturo Gómez Pompa y el Dr. José Sarukhán. Colectaba plantas, le pagaban y además hizo su tesis dirigida por el segundo, el trabajo fue "Ecología humana del Ejido Benito Juárez o Sebastopol, Tuxtepec, Oaxaca”, estudio pionero 
en el campo de la Ecología Humana y la Etnobotánica en México, con el cual se graduó de Biólogo en 1970. En México estaban recientes las heridas del movimiento de 1968 y Miguel Ángel congruente con sus ideas sociales se daba tiempo para participar en marchas que frecuentemente se realizaban en protesta por los diversos atropellos sufridos.

Los estudios de la Maestría en Ciencias los realizó en el Colegio de Posgraduados de Chapingo y en el Colegio Superior de Agricultura Tropical en Cárdenas, Tabasco, siendo su director de tesis el Dr. Efraím Hernández Xolocotzi y recibió el grado de Maestro en Ciencias en 1971, con la defensa de la tesis "Ecología Humana: Revisión del campo y programación del curso”, siendo ésta la que conforma los cimientos para la elaboración e impartición del curso de Etnobotánica en el Colegio de Posgraduados de Chapingo. La estancia en Tabasco fue difícil para Miguel Ángel debido a que su salud se vio disminuida, pues se infectó de Leishmania y se volvió sordo de un oído, sin embargo amaba ese estado de la República y de ahí se acrecentó su pasión por estudiar las zonas cálido-húmedas.

En los años 1972-1973, decidió cursar la Maestría en Antropología Social en la Universidad Iberoamericana, pensando que para su práctica profesional como etnobotánico tenía que entender desde la perspectiva antropológica a los grupos humanos. Bajo la dirección del Dr. Ángel Palerm, eminente antropólogo, desarrolló un ensayo sobre las "Castas de la India”, preocupado por la marcada diferenciación entre las clases sociales de esa nación. Después de 21 años de haber escrito ese ensayo, viajó a la India y, gracias a su memoria prodigiosa, que se acordaba de todo lo que había leído, en esas épocas de estudiante sobre ese país, disfrutó las manifestaciones culturales de la población hindú y, a la vez, sufrió, por comprobar la existencia todavía marcada de lo que fueron esas castas. En México los años setenta se caracterizaron por la influencia de la música latinoamericana y Miguel Ángel era un fanático de la música brasileña, Elis Regina, Chico Buarque, Milton Nascimento, entre otros.

El Doctorado en Ciencias lo cursó en la Facultad de Ciencias de la Universidad Nacional Autónoma de México (UNAM) en 1998 y su tesis denominada "Patrones de uso de plantas de la Sierra Norte de Puebla, México”, quedó en etapa de revisión por su jurado.

Los trabajos desempeñados por el maestro Miguel Ángel estuvieron relacionados con la enseñanza y la investigación donde el binomio hombre-planta o sociedad y naturaleza era el objetivo principal de estudio. Por ello los temas desarrollados en su vida laboral fueron la etnobotánica de las zonas cálido-húmedas, la agricultura tradicional, las plantas comestibles y medicinales, la etnobotánica histórica. 
En 1976 fue contratado como investigador en el Instituto Mexicano para el estudio de las plantas medicinales (IMEPLAM) y fue el primer etnobotánico profesional que sentó las bases para el trabajo etnobotánico médico. En ese mismo año ingresó a la UNAM como profesor para impartir por primera vez la cátedra de Etnobotánica y la Biología de campo "Uso y conocimiento diferenciado en una región cálido-húmeda de la Sierra Norte de Puebla”, donde dejó una impronta en sus alumnos que en la actualidad son reconocidos etnobotánicos, botánicos y etnobiólogos, como José Arellano, Arturo Argueta, Patricia Colunga, Carlos Gómez, Cristina Mapes, Martha Méndez, Guadalupe Miranda, Juan Manuel Rodríguez, Lourdes Villers, Sergio Zamudio y Daniel Zizumbo.

Aparte de la Facultad de Ciencias de la Universidad Nacional Autónoma de México, en esta faceta de maestro dictó cursos en diversas lnstituciones de Educación Superior tales como la Universidad Autónoma Metropolitana-Unidad Iztapalapa, la Escuela Nacional de Antropología e Historia, la FES-Iztacala, la FES-Aragón, las Escuelas de Agronomía de Chihuahua, Coahuila, Michoacán, Nuevo León, la Universidad Autónoma de Chiapas, la Universidad Autónoma del Estado de México, la Universidad Autónoma de Guerrero y la Universidad Autónoma de Tabasco. En ellas impartió Etnobotánica, Botánica Económica, Fisiología Vegetal, Arqueobotánica, Ecología Vegetal, Manejo de Ecosistemas y Agricultura Tradicional. A nivel internacional dictó el curso de Etnobotánica en la Universidad de Popayán, Colombia y en el Jardín Botánico de Córdoba, España.

Una característica de las charlas y de los cursos de Miguel Ángel era hablar de su querido maestro Efraím Hernández Xolocotzi, siempre lo ponía de ejemplo como un ser sabio y crítico. Otra característica de él era aceptar a todos los estudiantes, no importando si eran brillantes o no, siempre los atendía por igual y les prestaba todo su tiempo, compartiendo su conocimiento en todo momento, al igual que les respetaba su individualidad. Aquí se despertó su espíritu de mecenas y comenzó a apoyar a estudiantes y a artistas jóvenes.

A partir del año 1978 ingresó al Instituto de Biología de la Universidad Nacional Autónoma de México llegando a ser director del Jardín Botánico del mismo instituto de los años 1987 a 1990.

La multidisciplina siempre fue un factor que sobresalía en sus proyectos como el de "Naturaleza, Sociedad y Cultura en la Sierra Norte de Puebla” (1985-1987) que lo realizó con el antropólogo Dr. Elio Masferrer Kan y el proyecto "Formación de promotores comunitarios indígenas en el estado de Oaxaca” (1991-1994) trabajando con el médico Alberto Yzunsa Ogazón, en el Centro de Capacitación Integral para promotores comunitarios (CECIPROC), proyecto que obtuvo el Premio Nacional de 
Investigación Comunitaria de la Fundación para la Investigación Comunitaria y los Laboratorios Glaxo. De los proyectos binacionales que realizó se tiene "Conocimiento y manejo del germoplasma nativo entre comunidades indígenas” (1991-1992) siendo responsable conjuntamente con la Dra. Olga Lucía Sanabria Diago de Colombia. Como profesionista etnobotánico, en todos estos proyectos cumplió con uno de sus objetivos que consistió en integrar las ciencias naturales con las ciencias sociales para comprender los problemas de las comunidades rurales involucradas en estos trabajos y en procurar que los resultados de estos estudios dieran la pauta para la solución a su problemática.

El proyecto "Inventario de frutales en huertos y cafetales de la Sierra Norte de Puebla” (2003-2005) fue el último que concluyó con sus queridos discípulos y colegas, los Maestros en Ciencias Francisco Basurto, Virginia Evangelista y la Bióloga Myrna Mendoza.

Respecto a sus publicaciones destacan el libro basado en su tesis de licenciatura que lleva el mismo título y que ya entra en los llamados clásicos de la Etnobotánica Mexicana; otro libro que disfrutó al escribirlo dada su amplia cultura biológica y antropológica fue "Contribuciones Iberoamericanas al mundo: botánica, medicina, agricultura”, así como el “Catálogo de Plantas Útiles de la Sierra Norte de Puebla”. En este rubro de las publicaciones es digno de resaltar que cuando escribió un artículo sobre la lengua náhuatl, reconoció que los primeros autores del trabajo debían ser los campesinos que le proporcionaron la información al respecto de la nomenclatura florística náhuatl.

Formador de muchos jóvenes, dirigió 34 tesis de licenciatura y 8 de maestría, algunas de ellas fueron premiadas.

Miembro de diversas sociedades científicas, entre ellas, la Sociedad Botánica de México, la Sociedad de Historia y Filosofía de la Medicina, la International Society of Ethnobiology (de la que formó parte de diversas mesas directivas y fue delegado para América Latina), la Asociación Latinoamericana de Botánica, el Grupo Latinoamericano de Etnobotánica (del cual era representante para Norteamérica), y fue miembro del grupo de los Amigos del Natural History Museum de Londres. También formó parte de comités editoriales o consejos editoriales de diversas revistas científicas como Acta Botanica Mexicana, Etnobiología de México y el Journal of Ethnobiology and Ethnomedicine del Reino Unido.

En el IX Congreso Latinoamericano de Botánica realizado en la República Dominicana en el 2006 se le dio un reconocimiento por su labor etnobotánica y constancia. 
En este año 2007 se le han hecho reconocimientos póstumos, uno de ellos en el IV Congreso de la Asociación Colombiana de Botánica, en el país que el amó y se identificó con su población.

En México, en el VI Congreso de la Asociación Etnobiológica Mexicana, el pueblo Mixe le hizo una ofrenda, los colegas etnobiólogos le obsequiaron un papalote creado por el pintor oaxaqueño Francisco Toledo y se instauró el "Premio Miguel Ángel Martínez Alfaro” a la mejor tesis de licenciatura que concurse sobre temas etnobiológicos. El Colegio de Biólogos dio un reconocimiento a Miguel Ángel como Biólogo Distinguido.

Últimamente la Asociación Colombiana de Botánica estableció la "Cátedra Miguel Ángel Martínez Alfaro” para la impartición del curso de Etnobotánica Cualitativa que se dictará previo a los Congresos Nacionales de Botánica.

El maestro Miguel Ángel Martínez Alfaro muere de una insuficiencia renal súbita y paro al miocardio, el día 9 de febrero de 2007, en la Casa Fueguina de Coyoacán, donde vivió 27 años con la que esto escribe y donde compartimos la vida doméstica. Escribir sobre él es difícil para mí, creer que uno conoce a un ser humano de la talla de Miguel, es una falacia; quiero recordarlo como el amante de la música desde la culta hasta el rock ácido pasando por los ritmos tropicales, esforzándose por saber bailar, enseñándome a cocinar y a observar la bóveda celeste.

La verdad es que no lo conocí en el aspecto académico, la cotidianidad de la vida nos llevó a olvidarnos de lo que para muchos sería impensable, hacer a un lado la vida profesional.

Lo único que puedo decir es que el hombre con el cual viví fue extraordinario, fuera de serie, atípico, que rompía con las conductas trazadas o esquemas impuestos por la sociedad, desde su presencia física hasta la intelectual; un día lo veíamos con la cabeza rapada, otro con el cabello teñido de rojo o azul pasando por el naranja, idolatrando a sus musas, a las cuales les llamaba doctoras, Tina Turner o Nina Hagen. Atento, generoso y siempre dispuesto a ayudar a sus amigos y alumnos, e irritable contra las injusticias de este mundo.

Estoy segura que recordaremos a Miguel por su alegría de vivir, su calidad humana, su generosidad y simple y llanamente por haber sido un BUEN HOMBRE.

Abigail Aguilar Contreras. 